\title{
Acute post-streptococcal glomerulonephritis followed shortly by acute rheumatic fever
}

\author{
Y.L. Kwong, K.W. Chan ${ }^{1}$ and M.K. Chan \\ Departments of Medicine and 'Pathology, University of Hong Kong, Queen Mary Hospital, Hong Kong
}

\begin{abstract}
Summary: A 16 year old girl with post-streptococcal glomerulonephritis developed acute rheumatic fever 19 days afterwards. Previous publications on concurrent post-streptococcal glomerulonephritis and acute rheumatic fever are reviewed.
\end{abstract}

\section{Introduction}

Simultaneous occurrence of acute rheumatic fever and acute post-streptococcal glomerulonephritis is uncommon. We describe a patient with typical poststreptococcal glomerulonephritis who developed acute rheumatic fever 2 weeks after the initial renal manifestations.

\section{Case history}

A 16 year old Chinese girl was admitted complaining of puffiness of face and ankle swelling for 2 days following a sore throat 2 weeks before. She also noticed a decrease in urine output. Rashes and joint pain were absent and there was no relevant drug history.

Examination revealed pitting ankle oedema and facial puffiness. She was febrile. Joints were not inflamed. Blood pressure was $120 / 80 \mathrm{~mm} \mathrm{Hg}$. No subcutaneous nodules or skin lesions were detectable. Cardiovascular and abdominal examinations were normal. Urinalysis revealed abundant red cells with numerous red cell casts. Chest X-ray and electrocardiogram (ECG) were normal. Laboratory investigations revealed: haemoglobin $9.4 \mathrm{~g} / \mathrm{dl}$, white cell count $13.9 \times 10^{9} / 1$, antinuclear factor was negative; urea $3.4 \mathrm{mmol} / 1$, creatinine $63 \mu \mathrm{mol} / 1$, albumin $36 \mathrm{~g} / \mathrm{l}, \mathrm{C} 3$ $24 \mathrm{mg} / \mathrm{dl}$ (normal range $60-130), \mathrm{C} 417 \mathrm{mg} / \mathrm{dl}$ (1360 ), C-reactive protein was less than $0.5 \mathrm{mg} / \mathrm{dl}$, erythrocyte sedimentation rate (ESR) $78 \mathrm{~mm} / \mathrm{h}$, streptozyme $^{1}$ was positive $1: 100$. Throat swab culture was negative. Urine output was $500 \mathrm{ml}$ on the first day and 24 hour urine protein was $0.13 \mathrm{~g}$. A diagnosis of acute post-streptococcal glomerulonephritis was made.

She was treated with oral penicillin $500 \mathrm{mg}$ q.i.d. There was gradual improvement of urine output and

Correspondence: M.K. Chan, M.D., F.R.C.P.

Accepted: 4 September 1986 oedema subsided. C3 returned to normal.

Seventeen days after admission she noticed pain and swelling of her right knee associated with a fever of $38.5^{\circ} \mathrm{C}$. There was increased heat, decreased range of movement and effusion, of the joint which was tapped. The joint fluid was normal for complement, immunoglobulins and glucose. Antinuclear factor and culture were negative.

The next day as the arthritis in her right knee was beginning to abate, inflammation appeared in the right ankle. Cardiovascular examination then revealed a soft systolic murmur along the left sternal border. ECG revealed a PR interval of 0.2 seconds at a heart rate of around $110 / \mathrm{min}$. ESR rose to $113 \mathrm{~mm} / \mathrm{h}$. Creactive protein increased to $7.7 \mathrm{mg} / \mathrm{dl}$ and streptozyme titre was 1:200. Echocardiogram did not reveal any valvular lesion. The next day she developed arthritis of the left knee, while signs of inflammation involving the right knee and the ankle joints had largely subsided.

Acute rheumatic fever was diagnosed and aspirin $6 \mathrm{~g} /$ day given with such dramatic improvement of symptoms and arthritis that she became afebrile and asymptomatic 3 days afterwards. Urinalysis still revealed the presence of red cell casts which had become less numerous. A renal biopsy was performed 4 weeks after her initial renal manifestations. On light microscopy, there was diffuse proliferation with polymorphonuclear infiltration. Immunofluorescence showed staining with IgG and C3. Electron microscopy showed scattered intramembranous electron dense deposits.

On subsequent follow-up 2 weeks after her discharge, she was free from joint complaints. Urinalysis showed occasional red cells and the PR interval of her ECG decreased to 0.16 second, and the serum C3 was normal. She was put on monthly penicillin prophylaxis.

(C) The Fellowship of Postgraduate Medicine, 1987 


\section{Discussion}

Epidemiological surveys have suggested that 'nephritogenic' strains of streptococci do not cause acute rheumatic fever and 'rheumatogenic' strains do not lead to nephritis. ${ }^{2}$ While various renal pathologies have been described in acute rheumatic fever, and referred to as 'rheumatic nephritis', these are often non-specific and considered only a transient component of the acute illness of rheumatic fever. ${ }^{3}$ Acute poststreptococcal glomerulonephritis in association with rheumatic fever has been documented in only 3 patients. ${ }^{4,5}$

There is little doubt that our patient had poststreptococcal glomerulonephritis. She had oliguria and signs of fluid retention 2 weeks after a sore throat. Streptozyme was positive although the streptococcus could not be isolated. C3 was transiently but markedly depressed. The numerous red cell casts were evidence

\section{References}

1. Bisno, A.L. \& Ofek, I. Serologic diagnosis of streptococcal infection: comparison of a rapid hemagglutination technique with conventional antibody tests. $\mathrm{Am} \mathrm{J} \mathrm{Dis}$ Child 1974, 127: 676-681.

2. Stollerman, G.H. Rheumatogenic and nephritogenic streptococci. Circulation 1971, 43: 915-921.

3. Grishman, E., Cohen, S., Salomon, M.D. \& Churg, J. Renal lesions in acute rheumatic fever. Am J Pathol 1967, 51: $1045-1061$. of glomerular involvement. The light microscopy and immunofluorescent studies and the presence of elec- $\frac{\widehat{D}}{\mathrm{D}}$ tron-dense deposits on the glomerular basement mem- $\frac{\mathrm{a}}{c}$ brane were consistent with acute post-infectious. glomerulonephritis.

In our opinion the diagnosis of acute rheumatico fever was also firm. She did satisfy Jones' criteria ${ }^{6}$ since 0 she had migrating polyarthritis, prolonged PR $\frac{\overline{\bar{F}}}{\overline{7}}$ interval, increased ESR and C-reactive protein in the presence of a streptococcal infection. In all the repor- 0 ted cases of co-existent acute glomerulonephritis and acute rheumatic fever, ${ }^{4,5}$ acute rheumatic fever was the $\vec{O}$ presenting feature which was followed by glomerulo- $\vec{\overrightarrow{ }}$ nephritis. Our patient was unusual in that acuteo glomerulonephritis had preceded acute rheumatic fever. To the best of our knowledge this has never been 3 . reported. The present case confirms previous reports that, though rare, acute rheumatic fever and acute glomerulonephritis may occur together.

4. Gibney, R., Reineck, J., Bannayan, G.A. \& Stein, J.H.\ Renal lesions in acute rheumatic fever. Ann Intern Med 1981, 94: 322-326.

5. Ben-Dov, I., Berry, E.M. \& Kopolovic, J. Post-strep- $\vec{\bullet}$ tococcal nephritis and acute rheumatic fever in 2 adu Arch Intern Med 1985, 145: 338-339.

6. Stollerman, G.H., Markowitz, M., Taranta, A., Jones, J. Criteria (revised) for guidance in the diagnos of rheumatic fever. Circulation 1965, 32: 664-668. 